\title{
Diagnostic Accuracy of Fecal Calprotectin for the Detection of Small Bowel Crohn's Disease through Capsule Endoscopy: An Updated Meta-Analysis and Systematic Review
}

\author{
Eun Suk Jung ${ }^{1}$, Sang Pyo Lee", Sea Hyub Kae', Jung Han Kim², Hyeong Su Kim², and Hyun Joo Jang \\ ${ }^{1}$ Division of Gastroenterology, Department of Internal Medicine, Hallym University Dongtan Sacred Heart Hospital, Hallym University \\ College of Medicine, Hwaseong, and 2Division of Hematology-Oncology, Hallym University Kangnam Sacred Heart Hospital, Hallym \\ University College of Medicine, Seoul, Korea
}

See editorial on page 637.

\section{Article Info}

Received August 4, 2020

Revised September 21, 2020

Accepted October 27, 2020

Published online December 31, 2020

\section{Corresponding Author}

Hyeong Su Kim

ORCID https://orcid.org/0000-0003-0553-9008

E-mail nep2n@hallym.or.kr

\section{Hyun Joo Jang}

ORCID https://orcid.org/0000-0003-4424-1968

E-mail jhj1229@hallym.or.kr
Background/Aims: The diagnosis of small bowel Crohn's disease with negative ileocolonoscopic findings has been challenging. Fecal calprotectin (FC) has been used to detect colonic inflammation, but its efficacy for detecting small bowel inflammation is less established. We performed an updated meta-analysis to evaluate the diagnostic accuracy of $\mathrm{FC}$ to detect active small bowel inflammation observed during capsule endoscopy.

Methods: We conducted a systematic literature search for studies that evaluated the correlation between small bowel inflammation and FC in patients with suspected/established Crohn's disease. We calculated the pooled sensitivity, specificity, and diagnostic odds ratios (DORs) and constructed hierarchical summary receiver operating characteristic curves for FC cutoffs of 50 , 100 , and $200 \mu \mathrm{g} / \mathrm{g}$.

Results: Fourteen studies were eligible for the final analysis. The DORs of all FC cutoffs were significant. The highest DOR was observed at $100 \mu \mathrm{g} / \mathrm{g}$ (sensitivity, 0.73; specificity, 0.73; and DOR, 7.89) and was suggested as the optimal diagnostic cutoff. If we analyzed only studies that included patients with suspected Crohn's disease, the DOR was 8.96. If we analyzed only studies that included patients with a Lewis score $\geq 135$ as a diagnostic criterion for active disease, the DOR was 10.90 .

Conclusions: FC has significant diagnostic accuracy for detecting small bowel inflammation, and an FC cutoff of $100 \mu \mathrm{g} / \mathrm{g}$ can be used as a tool to screen for small bowel Crohn's disease. (Gut Liver 2021;15:732-741)

Key Words: Biomarker; Capsule endoscopy; Fecal calprotectin; Small bowel Crohn's disease

\section{INTRODUCTION}

Crohn's disease is a chronic inflammatory disorder that is usually accompanied by anemia, bloody stool, and weight loss. ${ }^{1}$ The presence of these symptoms is necessary to differentiate Crohn's disease from irritable bowel syndrome, with which Crohn's disease shares other symptoms such as abdominal pain, diarrhea, and bloating. It is difficult to differentiate Crohn's disease from irritable bowel syndrome in the absence of alarm symptoms. The small bowel is the most frequently involved site for Crohn's disease in both Asian $(72.8 \% \text { to } 91.7 \%)^{2-4}$ and Western popu- lations (41\% to $60.2 \%) .^{5-10}$ Ileocolonoscopy with biopsy is the gold standard to differentiate Crohn's disease from irritable bowel syndrome, but diagnosis can be challenging if ileocolonic manifestations are absent. ${ }^{11}$ Therefore, biomarkers to detect small bowel inflammation are being widely investigated.

Fecal calprotectin (FC) is a $36-\mathrm{kDa}$ protein secreted from stimulated neutrophils, ${ }^{12}$ and it can be used to distinguish inflammatory bowel disease from functional gastrointestinal disorders such as irritable bowel syndrome. ${ }^{13,14}$ In a metaanalysis of eight studies, a FC level of $\leq 40 \mu \mathrm{g} / \mathrm{g}$ excluded the likelihood that a patient had inflammatory bowel disease. ${ }^{15}$ 
Although FC can identify patients with small bowel inflammation, gastroduodenoscopy, colonoscopy, or small bowel capsule endoscopy are needed to correlate the diagnosis. ${ }^{16}$ The predictive value of FC is well established in patients with colonic involvement of Crohn's disease, ${ }^{17}$ and the addition of small bowel capsule endoscopy has been confirmed in several studies using inflammatory indices such as a Lewis score. ${ }^{16,18-25}$ Recent prospective studies have suggested that FC can be used as a screening tool before patients undergo capsule endoscopy; $;^{26-30}$ however, these studies have been limited by sample size and statistical power. Therefore, we conducted an updated meta-analysis to provide pooled diagnostic accuracy and a cutoff value of FC for the diagnosis of small bowel Crohn's disease.

\section{MATERIALS AND METHODS}

\section{Literature searching strategy}

A comprehensive literature search was performed on June 8, 2020, using PubMed, Embase, and the Cochrane Central Register of Controlled Trials in the Cochrane Library. This was a systematic review conducted according to the Preferred Reporting Items for Systematic Reviews and Meta-Analyses (PRISMA). ${ }^{31}$ We conducted a broad search using the terms "fecal calprotectin" and "capsule endoscopy" to capture as many number of citations as possible. Two authors (E.S.J. and H.J.J.) independently reviewed the titles and abstracts of all articles from the initial search and then reviewed the full text of articles of the most interest.
An independent evaluator (J.H.K.) resolved any disagreements.

\section{Selection criteria}

We included studies that met the following criteria: (1) the focus was FC and small bowel capsule endoscopy; (2) the design included randomized-controlled trials, open-label prospective studies, observational studies, or case-control studies; (3) the patients were undergoing evaluation for suspected Crohn's disease or reassessment of Crohn's disease activity; ${ }^{32,33}(4)$ there were 35 or more cases; and (5) full-text publications in English. We excluded studies that evaluated suspected small bowel malignancy or obscure gastrointestinal bleeding.

\section{Methodological quality assessment}

To evaluate the methodological quality of the included studies, the Quality Assessment of Diagnostic Accuracy Studies-2 (QUADAS-2) tool was used. Review Manager 5.4.0 (The Cochrane Collaboration, London, UK) was used to generate the summary figure of QUADAS-2 results.

\section{Data extraction, primary outcome, and additional analyses}

For each study, the number of true positive, false positive, false negative, and true negative results were extracted for FC level cutoffs of 50, 100, and $200 \mu \mathrm{g} / \mathrm{g}$ as available in each study.

The primary outcome of this study was diagnostic accuracy of FC to identify small bowel Crohn's disease or

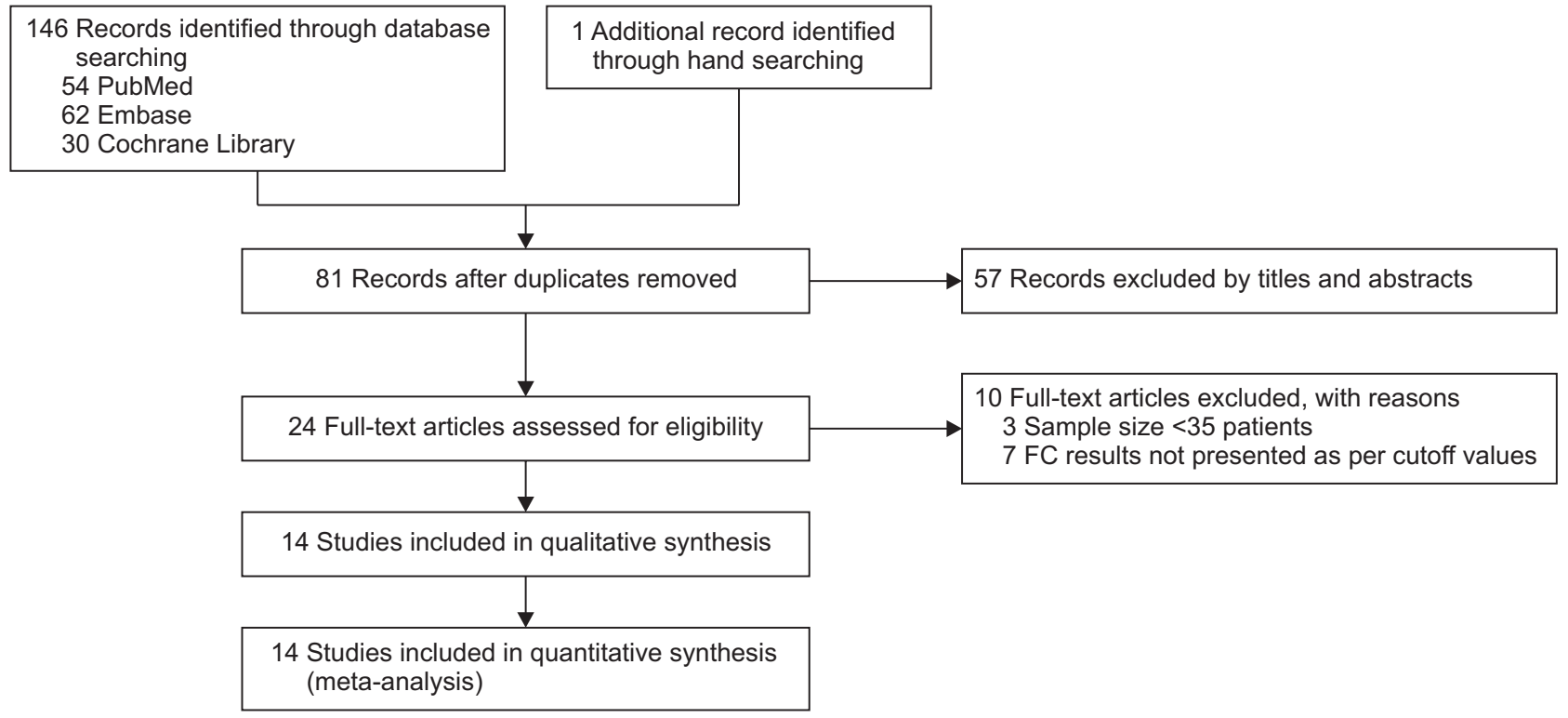

Fig. 1. Study flow diagram.

FC, fecal calprotectin. 


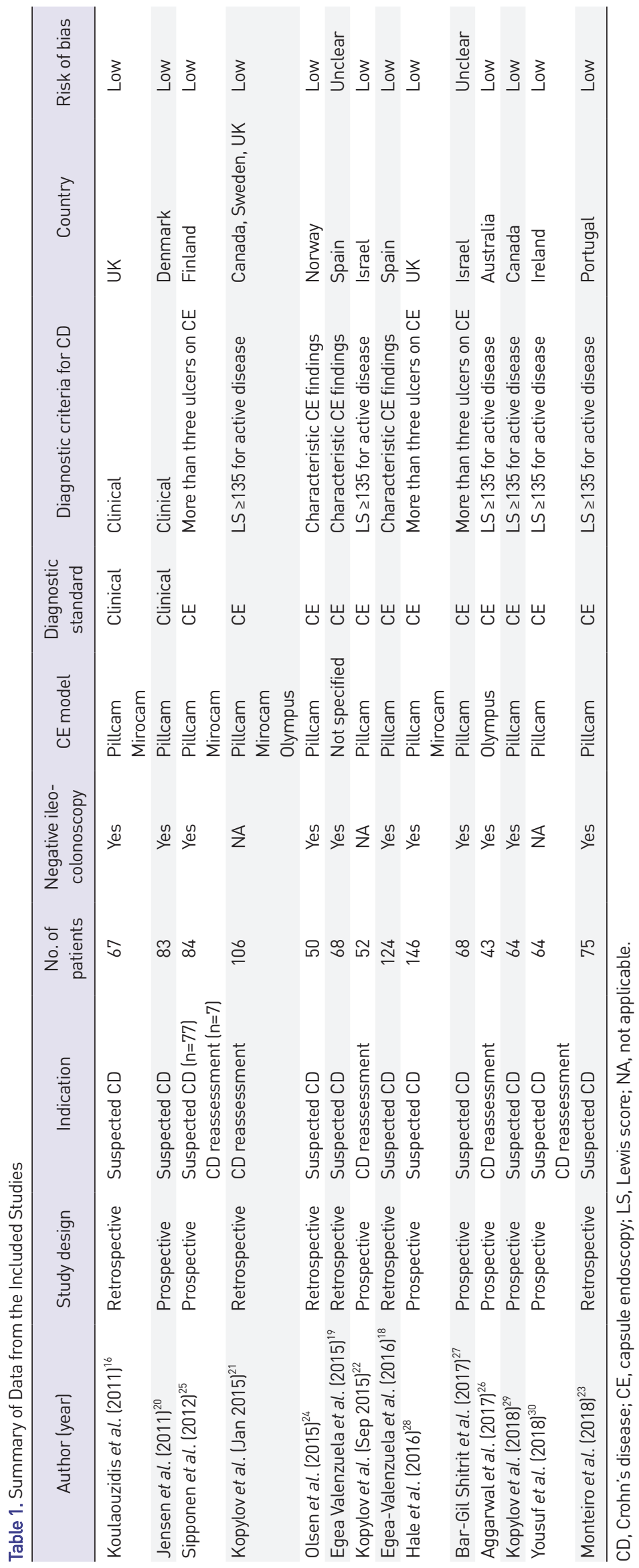


to find active inflammation of the small intestine in established Crohn's disease. The diagnosis of small bowel Crohn's disease was made by the criteria used in the original studies.

We also assessed the effects of the following covariates on the results: (1) study design (prospective vs retrospective); (2) study indication (suspected Crohn's disease vs Crohn's disease reassessment); (3) exclusion of patients with abnormal ileocolonoscopy; (4) definition of Crohn's disease (clinical vs capsule endoscopy); (5) diagnostic criteria for Crohn's disease (Lewis score $\geq 135$ ); and (6) bias assessment.

\section{Statistical analysis}

We calculated sensitivity, specificity, and diagnostic odds ratio (DOR), using only direct test comparisons. To quantify heterogeneity, the $\mathrm{I}^{2}$ statistic was used. A value of more than $50 \%$ was used as a threshold for high heterogeneity. Because of high heterogeneity, the DerSimonianLaird random-effects model was applied.

A bivariate model was used to assess the relationship between pooled sensitivity and false-positive rates. ${ }^{34}$ The model's parameter estimates were used to acquire hierar- chical summary receiver operating characteristic (HSROC) with $95 \%$ confidence intervals (CI) and a 95\% prediction region, defining the sensitivity and false-positive rate values within which we may expect the results of a future study results to lie. An estimated area under the curve (AUC) was used to measure test accuracy. Analyses were carried out using the meta ${ }^{35}$ and mada $^{36}$ packages in $\mathrm{R}$ version 4.0.2 and Review Manager 5.4.0.

\section{RESULTS}

\section{Study selection}

We identified 147 studies through the database search and manual searches. After removing 61 duplicates, the titles and abstracts of 81 articles were screened. A further 57 articles were removed, and we then reviewed the full text of 24 studies. Ten of these were removed, and 14 studies were finally included in the systematic review (Fig. 1). ${ }^{16,18-30}$

\section{Study characteristics}

There were eight prospective studies ${ }^{20,22,25-30}$ and six retrospective studies ${ }^{16,18,19,21,23,24}$ (Table 1). Three studies

$\begin{array}{lrrrrrr}\text { Study } & \text { TP } & \text { FP } & \text { FN } & \text { TN Sensitivity }(95 \% \mathrm{Cl}) & \text { Specificity }(95 \% \mathrm{CI}) \\ \text { Egea-Valenzuela et al. [2015] } & 27 & 31 & 1 & 9 & 0.96[0.82,1.00] & 0.23[0.11,0.38] \\ \text { Hale et al. [2016] }^{28} & 16 & 96 & 2 & 32 & 0.89[0.65,0.99] & 0.25[0.18,0.33] \\ \text { Jensen et al. [2011] } & 38 & 19 & 2 & 24 & 0.95[0.83,0.99] & 0.56[0.40,0.71] \\ \text { Kopylov et al. [Jan 2015] }^{21} & 73 & 18 & 10 & 5 & 0.88[0.79,0.94] & 0.22[0.07,0.44] \\ \text { Kopylov et al. [Sep 2015] }^{22} & 32 & 2 & 12 & 6 & 0.73[0.57,0.85] & 0.75[0.35,0.97] \\ \text { Koulaouzidis et al. [2011] }^{16} & 15 & 29 & 0 & 23 & 1.00[0.78,1.00] & 0.44[0.30,0.59] \\ \text { Monteiro et al. [2018] }^{23} & 36 & 13 & 6 & 19 & 0.86[0.71,0.95] & 0.59[0.41,0.76] \\ \text { Olsen et al. [2015] }^{24} & 8 & 8 & 4 & 30 & 0.67[0.35,0.90] & 0.79[0.63,0.90] \\ \text { Sipponen et al. [2012] }^{25} & 10 & 21 & 4 & 49 & 0.71[0.42,0.92] & 0.70[0.58,0.80] \\ \text { Yousuf et al. [2018] }^{30} & 9 & 19 & 6 & 30 & 0.60[0.32,0.84] & 0.61[0.46,0.75]\end{array}$

Sensitivity $(95 \% \mathrm{Cl})$ Specificity $(95 \% \mathrm{Cl})$

TP FP FN TN Sensitivity $(95 \% \mathrm{Cl})$ Specificity $(95 \% \mathrm{Cl})$

Hale et al. [2016]

Jensen et al. [2011]

$\begin{array}{llll}16 & 96 & 2 & 32\end{array}$

$0.89[0.65,0.99]$

$0.25[0.18,0.33]$

$0.56[0.40,0.71]$

$0.22[0.07,0.44]$

$0.75[0.35,0.97]$

$0.44[0.30,0.59]$

$0.59[0.41,0.76]$

$0.79[0.63,0.90]$

$0.61[0.46,0.75]$
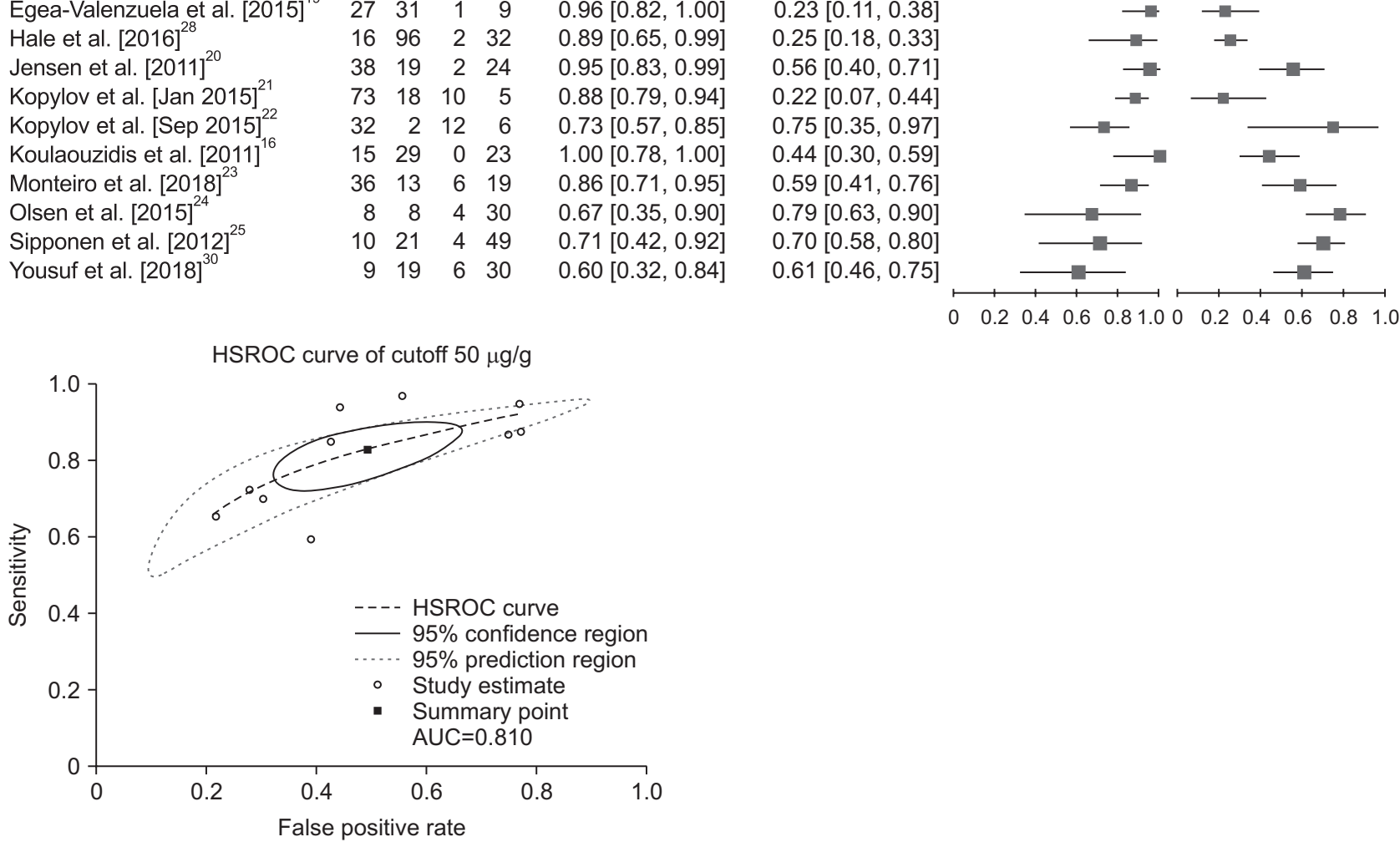

Fig. 2. Forest plot and HSROC curve showing the diagnostic accuracy of a fecal calprotectin cutoff of $50 \mu \mathrm{g} / \mathrm{g}$ for detecting small bowel Crohn's disease. TP, true positive; FP, false positive; FN, false negative; TN, true negative; $\mathrm{Cl}$, confidence interval; HSROC, hierarchical summary receiver operating characteristic; AUC, area under the curve. 
included patients evaluated for reassessment of Crohn's disease; ${ }^{21,22,26}$ nine studies included patients with suspected Crohn's diseases; ${ }^{16,18-20,23,24,27-29}$ and two studies included both patient groups. ${ }^{25,30}$ Most studies included patients with negative ileocolonoscopies, ${ }^{16,18-20,23-29}$ although three studies were not applicable due to lack of information. ${ }^{21,22,30}$ Two studies used clinical diagnosis, ${ }^{16,20}$ but 12 studies used capsule endoscopy-based diagnosis. . $^{18,19,21-30}$ Twelve studies had a low risk of bias ${ }^{16,18,20-26,28-30}$ although the bias risks of two studies were unclear. ${ }^{19,27}$

\section{Diagnostic accuracy of the $\mathbf{5 0} \boldsymbol{\mu g} / \mathrm{g}$ FC level}

We assessed 10 studies with a total of 794 patients to evaluate the diagnostic accuracy of FC with a cutoff value of $50 \mu \mathrm{g} / \mathrm{g}$ (Fig. 2). This cutoff had a sensitivity of $83 \%$ (95\%
CI, $74 \%$ to $90 \%$ ); specificity of $50 \%$ (95\% CI, $36 \%$ to $64 \%$ ); and DOR of 5.52 (95\% CI, 3.31 to 9.19) (Table 2). The partial AUC of the HSROC was 0.81 (Fig. 2).

\section{Diagnostic accuracy of the $100 \mu \mathrm{g} / \mathrm{g}$ FC level}

We assessed 12 studies with 961 patients to evaluate the diagnostic accuracy of FC with a cutoff value of $100 \mu \mathrm{g} / \mathrm{g}$ (Fig. 3). At this level, FC had a sensitivity of 73\% (95\% CI, $66 \%$ to $78 \%$ ); specificity of $73 \%$ ( $95 \%$ CI, $62 \%$ to $81 \%$ ); and DOR of 7.89 (95\% CI, 4.32 to 14.44) (Table 2). The partial AUC of the HSROC was 0.72 (Fig. 3).

\section{Diagnostic accuracy of the $\mathbf{2 0 0} \mu \mathrm{g} / \mathrm{g}$ FC level}

We assessed seven studies with 594 patients to evaluate the diagnostic accuracy of FC with a cutoff value of 200

Table 2. Diagnostic Accuracy of FC for the Detection of Small Bowel Crohn's Disease through Capsule Endoscopy

\begin{tabular}{cccccccc}
\hline FC cutoff & No. of studies & No. of patients & Sensitivity (95\% CI) & Specificity (95\% CI) & DOR (95\% CI) & AUC & Partial AUC \\
\hline $50 \mu \mathrm{g} / \mathrm{g}$ & 10 & 794 & $0.831(0.740-0.895)$ & $0.502(0.359-0.644)$ & $5.517(3.313-9.186)$ & 0.774 & 0.810 \\
$100 \mu \mathrm{g} / \mathrm{g}$ & 12 & 961 & $0.725(0.657-0.784)$ & $0.728(0.622-0.814)$ & $7.894(4.315-14.440)$ & 0.763 & 0.722 \\
$200 \mu \mathrm{g} / \mathrm{g}$ & 7 & 594 & $0.495(0.361-0.629)$ & $0.882(0.738-0.952)$ & $7.205(2.681-19.366)$ & 0.670 & 0.579 \\
\hline
\end{tabular}

FC, fecal calprotectin; $\mathrm{Cl}$, confidence interval; DOR, diagnostic odds ratio; $\mathrm{AUC}$, area under the curve.

$\begin{array}{lrrrrr}\text { Study } & \text { TP } & \text { FP } & \text { FN } & \text { TN Sensitivity }(95 \% \text { Cl) } \\ \text { Aggarwal et al. [2017] }^{26} & 22 & 0 & 4 & 17 & 0.85[0.65,0.96] \\ \text { Bar-Gil Shitrit et al. [2017] }^{27} & 18 & 18 & 5 & 27 & 0.78[0.56,0.93] \\ \text { Egea-Valenzuela et al. [2015] }^{19} & 21 & 13 & 7 & 27 & 0.75[0.55,0.89] \\ \text { Egea Valenzuela et al. [2016] }^{18} & 33 & 19 & 10 & 62 & 0.77[0.61,0.88] \\ \text { Hale et al. [2016] }^{28} & 13 & 60 & 5 & 68 & 0.72[0.47,0.90] \\ \text { Kopylov et al. [Jan 2015] }^{21} & 64 & 16 & 19 & 7 & 0.77[0.67,0.86] \\ \text { Kopylov et al. [Sep 2015] }^{22} & 25 & 0 & 19 & 8 & 0.57[0.41,0.72] \\ \text { Kopylov et al. [2018] }^{29} & 20 & 5 & 7 & 32 & 0.74[0.54,0.89] \\ \text { Koulaouzidis et al. [2011] }^{16} & 15 & 20 & 0 & 32 & 1.00[0.78,1.00] \\ \text { Monteiro et al. [2018] }^{23} & 33 & 4 & 9 & 29 & 0.79[0.63,0.90] \\ \text { Sipponen et al. [2012] }^{25} & 7 & 8 & 7 & 62 & 0.50[0.23,0.77] \\ \text { Yousuf et al. [2018] }^{30} & 8 & 12 & 7 & 37 & 0.53[0.27,0.79]\end{array}$

HSROC curve of cutoff $100 \mu \mathrm{g} / \mathrm{g}$

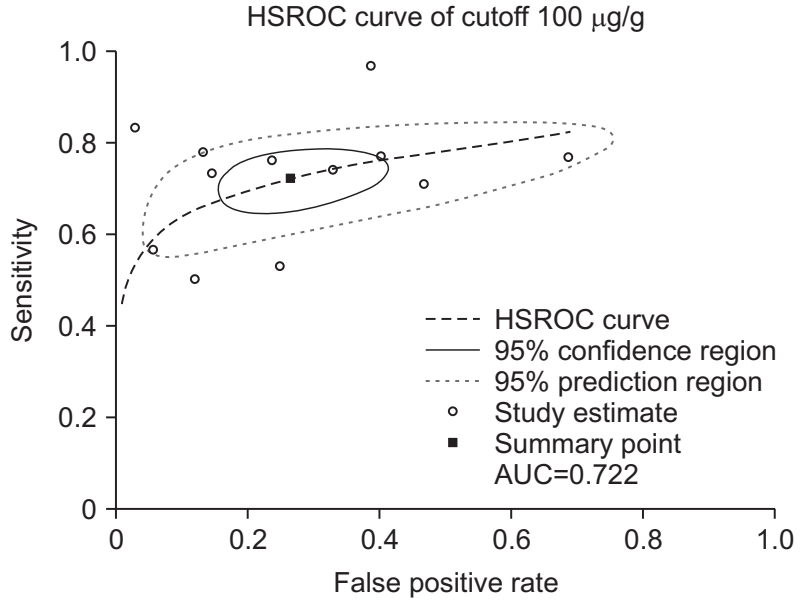

Specificity $(95 \% \mathrm{Cl}) \quad$ Sensitivity $(95 \% \mathrm{Cl}) \quad$ Specificity $(95 \% \mathrm{Cl})$

$1.00[0.80,1.00]$

$0.60[0.44,0.74]$

$0.68[0.51,0.81]$

$0.77[0.66,0.85]$

$0.53[0.44,0.62]$

$0.30[0.13,0.53]$

$1.00[0.63,1.00]$

$0.86[0.71,0.95]$

$0.62[0.47,0.75]$

$0.88[0.72,0.97]$

$0.89[0.79,0.95]$

$0.76[0.61,0.87]$

Fig. 3. Forest plot and HSROC curve showing the diagnostic accuracy of a fecal calprotectin cutoff of $100 \mu \mathrm{g} / \mathrm{g}$ for detecting small bowel Crohn's disease. TP, true positive; FP, false positive; FN, false negative; TN, true negative; $\mathrm{Cl}$, confidence interval; HSROC, hierarchical summary receiver operating characteristic; AUC, area under the curve. 
$\mu \mathrm{g} / \mathrm{g}$ (Fig. 4). At this level, FC had a sensitivity of 50\% (95\% CI, $36 \%$ to $63 \%$ ); specificity of $88 \%$ ( $95 \%$ CI, $74 \%$ to $95 \%$ ); and DOR of 7.21 (95\% CI, 2.68 to 19.37) (Table 2). The partial AUC of the HSROC was 0.58 (Fig. 4).

\section{Subgroup analyses}

Although partial AUC with a $50 \mu \mathrm{g} / \mathrm{g}$ cutoff was the highest, the specificity at this level was relatively low. The difference between the partial AUC of cutoff levels of 100 $\mu \mathrm{g} / \mathrm{g}$ and $50 \mu \mathrm{g} / \mathrm{g}$ was not large; moreover, the specificity and DOR was relatively high at $100 \mu \mathrm{g} / \mathrm{g}$. Therefore, 100 $\mu \mathrm{g} / \mathrm{g}$ was considered an optimal cutoff value. Subsequent subgroup analyses were only performed at the $100 \mu \mathrm{g} / \mathrm{g}$ level.
In the subgroup analyses, results remained statistically significant except in the studies that reassessed Crohn's disease (Table 3 ). The prospective studies had a sensitivity of 0.68 and specificity of 0.73 (DOR of 7.52). The retrospective studies had a sensitivity of 0.78 and specificity of 0.67 (DOR of 8.41). The studies for patients with suspected Crohn's disease had a sensitivity of 0.75 and specificity of 0.74 (DOR of 8.96). The studies that included only patients with normal ileocolonoscopies had a sensitivity of 0.76 and specificity of 0.75 (DOR of 10.07). The studies for patients with active disease that used a Lewis score of 135 or higher as a diagnostic criterion had a sensitivity of 0.72 and specificity of 0.81 (DOR of 10.90).

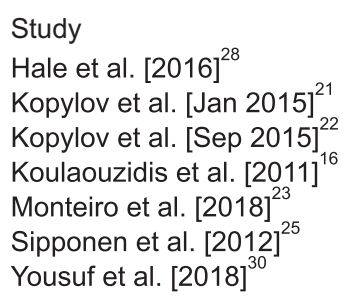

$\begin{array}{rrrrr}\text { TP } & \text { FP } & \text { FN } & \text { TN Sensitivity }(95 \% \text { Cl) Sp } \\ 9 & 30 & 9 & 98 & 0.50[0.26,0.74] \\ 53 & 13 & 30 & 10 & 0.64[0.53,0.74] \\ 14 & 0 & 30 & 8 & 0.32[0.19,0.48] \\ 10 & 3 & 5 & 49 & 0.67[0.38,0.88] \\ 26 & 2 & 16 & 31 & 0.62[0.46,0.76] \\ 2 & 1 & 12 & 69 & 0.14[0.02,0.43] \\ 7 & 5 & 8 & 44 & 0.47[0.21,0.73]\end{array}$

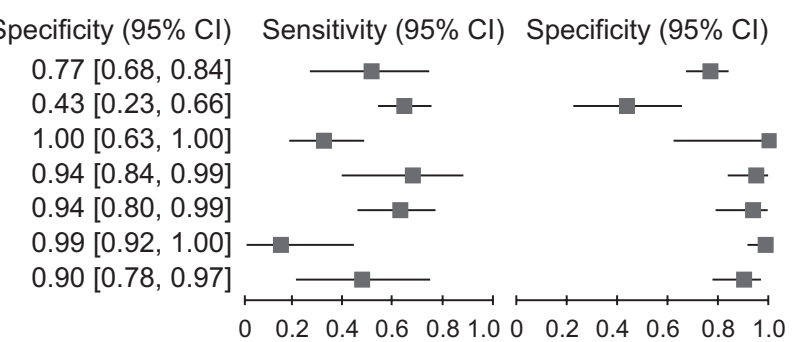

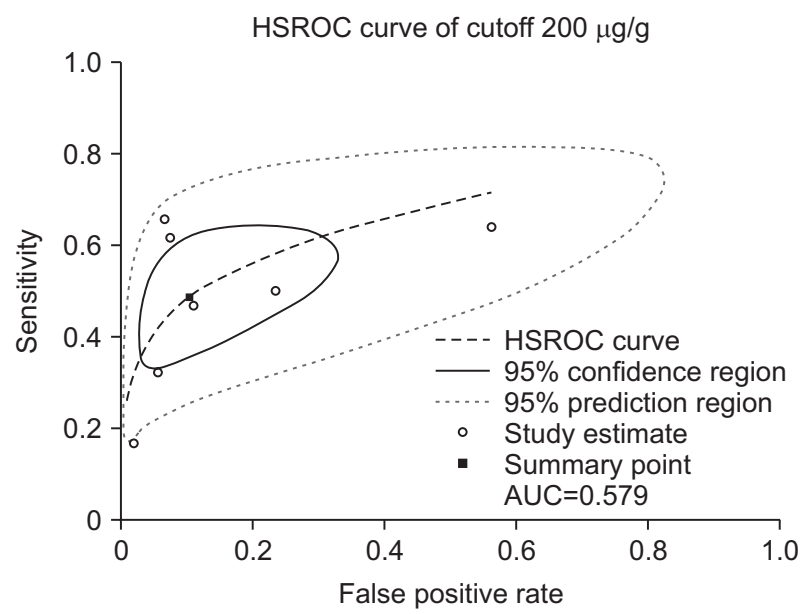

Fig. 4. Forest plot and HSROC curve showing the diagnostic accuracy of a fecal calprotectin cutoff of $200 \mu \mathrm{g} / \mathrm{g}$ for detecting small bowel Crohn's disease. TP, true positive; FP, false positive; FN, false negative; TN, true negative; $\mathrm{Cl}$, confidence interval; HSROC, hierarchical summary receiver operating characteristic; AUC, area under the curve.

Table 3. Diagnostic Accuracy of Fecal Calprotectin for the Detection of Small Bowel Crohn's Disease through Capsule Endoscopy by Subgroup Analyses

\begin{tabular}{lccccc}
\hline \multicolumn{1}{c}{ Subgroup } & No. of studies & No. of patients & Sensitivity (95\% CI) & Specificity (95\% CI) & DOR (95\% CI) \\
\hline Prospective & 7 & 521 & $0.675(0.568-0.767)$ & $0.728(0.622-0.814)$ & $7.518(3.574-15.814)$ \\
Retrospective & 5 & 440 & $0.776(0.713-0.828)$ & $0.667(0.497-0.803)$ & $8.406(2.831-24.958)$ \\
Suspected CD & 8 & 696 & $0.746(0.678-0.805)$ & $0.735(0.624-0.823)$ & $8.961(5.260-15.266)$ \\
CD reassessment & 3 & 201 & $0.730(0.552-0.855)$ & $0.836(0.173-0.992)$ & $13.941(0.657-259.924)$ \\
Negative ileocolonoscopy & 9 & 739 & $0.757(0.692-0.811)$ & $0.750(0.639-0.835)$ & $10.065(5.589-18.125)$ \\
CE & 11 & 894 & $0.719(0.654-0.776)$ & $0.743(0.625-0.833)$ & $7.375(4.015-13.546)$ \\
LS $\geq 135$ for active disease & 6 & 404 & $0.718(0.616-0.802)$ & $0.806(0.579-0.926)$ & $10.898(3.024-39.276)$ \\
Low risk of bias & 10 & 825 & $0.718(0.629-0.788)$ & $0.754(0.625-0.849)$ & $8.955(4.181-19.180)$ \\
\hline
\end{tabular}

$\mathrm{Cl}$, confidence interval; DOR, diagnostic odds ratio; CD, Crohn's disease; CE, capsule endoscopy; LS, Lewis score. 


\section{Bias assessment of included studies}

The QUADAS-2 assessment is summarized in Fig. 5. The included studies were of good quality and had a low risk of bias.

\section{DISCUSSION}

Our study demonstrated a strong correlation between FC levels and active inflammation in the small bowel as diagnosed by small bowel capsule endoscopy. The diagnosis of small bowel Crohn's disease with a normal ileocolonoscopy is challenging. To address this issue, cross-sectional imaging techniques such as computed tomographic enterography or magnetic resonance enterography are used, although these techniques have less sensitivity for detecting subtle mucosal inflammation in the small bowel. ${ }^{37-39}$ Small bowel capsule endoscopy is a preferred method for detecting small bowel inflammation, but it is not readily available, is expensive, and presents a risk of small bowel obstruction; ${ }^{40}$ therefore, biomarkers such as FC have become an inexpensive and simple screening tool.

FC is a useful surrogate marker to detect bowel inflammation and to diagnose and monitor patients with inflammatory bowel diseases. ${ }^{22,41-45}$ Mosli et al. ${ }^{42}$ reported that endoscopic activity in symptomatic patients with inflammatory bowel diseases could be detected by FC with a pooled sensitivity of 0.88 (95\% CI, 0.84 to 0.90$)$ and

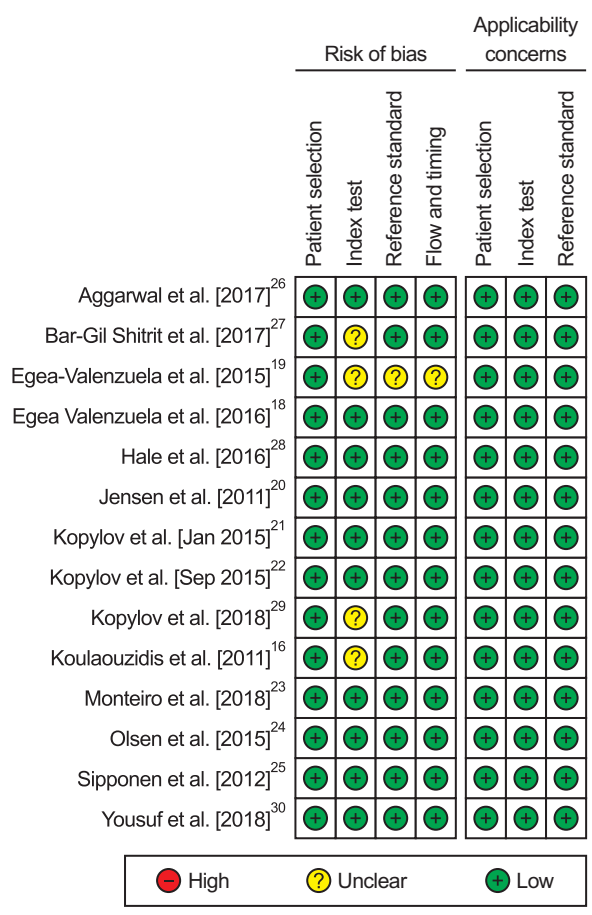

Fig. 5. Quality Assessment of Diagnostic Accuracy Studies-2 for evaluating methodology quality. specificity of 0.73 (95\% CI, 0.66 to 0.79 ). Another recent meta-analysis showed that an FC cutoff of $150 \mu \mathrm{g} / \mathrm{g}$ could be used to detect a postoperative endoscopic recurrence of Crohn's disease (pooled sensitivity was 0.70 [95\% CI, 0.59 to 0.81 ], specificity 0.69 [95\% CI, 0.61 to 0.77 ], and DOR 0.92 [95\% CI, 2.61 to 12.17$])^{46}$

Researchers disagree on whether FC can accurately detect intestinal inflammation in both the small and large bowels. Some studies report that FC can detect Crohn's disease throughout the intestinal tract, ${ }^{20,47}$ but others have suggested a lower degree of accuracy for diagnosis in the small intestine. ${ }^{19,48}$ The preferred FC cutoff value to detect small bowel inflammation is also unresolved. A recent meta-analysis of seven studies with 463 patients suggested that an FC level of $50 \mu \mathrm{g} / \mathrm{g}$ could detect small bowel Crohn's disease. ${ }^{49}$ However, this study was limited because it only included a small number of studies and only three prospective studies.

Our pooled data indicate that an FC cutoff of $100 \mu \mathrm{g} /$ $\mathrm{g}$ is associated with optimal diagnostic accuracy for active small bowel inflammation. When we compared three FC cutoff levels, a higher level was generally associated with decreasing sensitivity and increasing specificity (Fig. 6). Although the sensitivity of the $50 \mu \mathrm{g} / \mathrm{g}$ cutoff was the highest among the three cutoffs, the specificity was relatively low (0.50). A cutoff of $100 \mu \mathrm{g} / \mathrm{g}$ had relatively high sensitivity and specificity among the three measurements. Moreover, the DOR for a $100 \mu \mathrm{g} / \mathrm{g}$ cutoff was higher than the $50 \mu \mathrm{g} / \mathrm{g}$ cutoff. Therefore, we suggest that an FC cutoff of $100 \mu \mathrm{g} / \mathrm{g}$ has the most advantageous screening value for small bowel inflammation.

Our meta-analysis study has some limitations. We included retrospective studies along with prospective studies because of the low number of available studies. If we looked at only the eight prospective studies that were

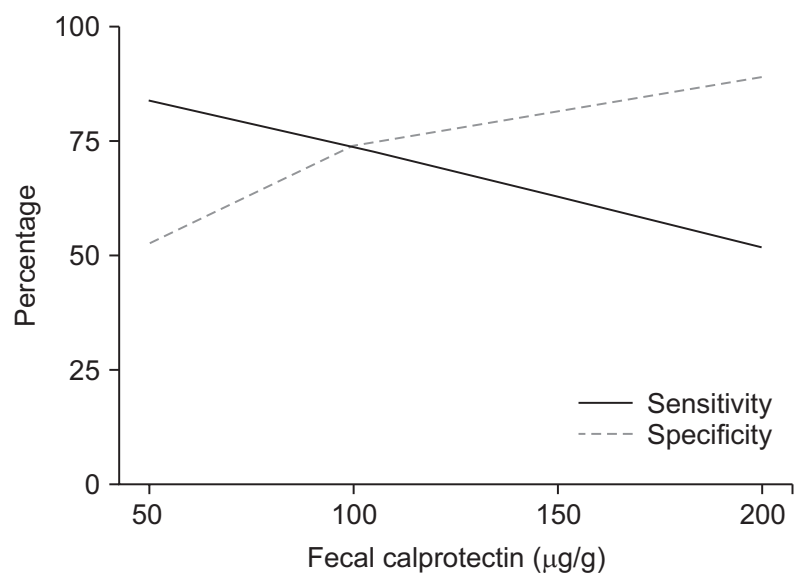

Fig. 6. Graph of sensitivities and specificities from three fecal calprotectin cutoffs $(50,100$, and $200 \mu \mathrm{g} / \mathrm{g})$. 
included, the DOR was still significant. Furthermore, an indication of capsule endoscopy and diagnostic criteria of Crohn's disease on small bowel capsule endoscopy were not identical. Our subgroup analyses showed that an FC cutoff of $100 \mu \mathrm{g} / \mathrm{g}$ had significant accuracy in diagnosing suspected Crohn's disease but was not significant for reassessing Crohn's disease; however, we only had three studies that reassessed Crohn's disease, and the DOR was affected by the results of one study. The findings would have been significant if more studies were included. In another subgroup analysis, $\mathrm{FC}$ with a cutoff of $100 \mu \mathrm{g} / \mathrm{g}$ was significant in the studies using a Lewis score of 135 or higher as diagnostic criteria for active disease.

Despite these limitations, and to the best of our knowledge, our meta-analysis study on the diagnostic accuracy of FC for small bowel inflammation includes the largest number of studies correlating FC and small bowel inflammation on capsule endoscopy.

In conclusion, an FC cutoff of $100 \mu \mathrm{g} / \mathrm{g}$ had the highest diagnostic accuracy and could be used as a screening tool to detect small bowel Crohn's disease.

\section{CONFLICTS OF INTEREST}

No potential conflict of interest relevant to this article was reported.

\section{AUTHOR CONTRIBUTIONS}

Conception and design of the study: E.S.J., H.J.J. Data collection: E.S.J., J.H.K., H.J.J. Statistical analysis: E.S.J., H.S.K., H.J.J. Interpretation of data: E.S.J., S.P.L., S.H.K., H.S.K. Writing of the draft manuscript: E.S.J. Approval of the final version of the manuscript: H.S.K., H.J.J. Supervision: H.S.K., H.J.J.

\section{ORICD}

Eun Suk Jung Sang Pyo Lee Sea Hyub Kae Jung Han Kim Hyeong Su Kim Hyun Joo Jang https://orcid.org/0000-0001-5039-7876 https://orcid.org/0000-0002-4495-3714 https://orcid.org/0000-0003-3101-1135 https://orcid.org/0000-0002-9134-1761 https://orcid.org/0000-0003-0553-9008 https://orcid.org/0000-0003-4424-1968

\section{REFERENCES}

1. Torres J, Mehandru S, Colombel JF, Peyrin-Biroulet L. Crohn's disease. Lancet 2017;389:1741-1755.

2. Abdul-Baki H, ElHajj I, El-Zahabi LM, et al. Clinical epidemiology of inflammatory bowel disease in Lebanon. Inflamm Bowel Dis 2007;13:475-480.

3. Park SH, Kim YJ, Rhee KH, et al. A 30-year trend analysis in the epidemiology of inflammatory bowel disease in the Songpa-Kangdong District of Seoul, Korea in 1986-2015. J Crohns Colitis 2019;13:1410-1417.

4. Baik SH, Park KJ, Lee KY, et al. Characteristic phenotypes in Korean Crohn's disease patients who underwent intestinal surgery for the treatment. J Korean Med Sci 2013;28:575-579.

5. Gower-Rousseau C, Vasseur F, Fumery M, et al. Epidemiology of inflammatory bowel diseases: new insights from a French population-based registry (EPIMAD). Dig Liver Dis 2013;45:89-94.

6. Nuij VJ, Zelinkova Z, Rijk MC, et al. Phenotype of inflammatory bowel disease at diagnosis in the Netherlands: a population-based inception cohort study (the Delta Cohort). Inflamm Bowel Dis 2013;19:2215-2222.

7. Sjöberg D, Holmström T, Larsson $M$, et al. Incidence and clinical course of Crohn's disease during the first year: results from the IBD Cohort of the Uppsala Region (ICURE) of Sweden 2005-2009. J Crohns Colitis 2014;8:215-222.

8. Lapidus A. Crohn's disease in Stockholm County during 1990-2001: an epidemiological update. World J Gastroenterol 2006;12:75-81.

9. Vind I, Riis L, Jess T, et al. Increasing incidences of inflammatory bowel disease and decreasing surgery rates in Copenhagen City and County, 2003-2005: a population-based study from the Danish Crohn colitis database. Am J Gastroenterol 2006;101:1274-1282.

10. Björnsson S, Jóhannsson JH. Inflammatory bowel disease in Iceland, 1990-1994: a prospective, nationwide, epidemiological study. Eur J Gastroenterol Hepatol 2000;12:31-38.

11. Van Assche G, Dignass A, Panes J, et al. The second European evidence-based consensus on the diagnosis and management of Crohn's disease: definitions and diagnosis. J Crohns Colitis 2010;4:7-27.

12. Basso D, Zambon CF, Plebani M. Inflammatory bowel diseases: from pathogenesis to laboratory testing. Clin Chem Lab Med 2014;52:471-481.

13. Lichtenstein GR, Loftus EV, Isaacs KL, Regueiro MD, Gerson LB, Sands BE. ACG clinical guideline: management of Crohn's disease in Adults. Am J Gastroenterol 2018;113:481517.

14. Sipponen T. Diagnostics and prognostics of inflammatory bowel disease with fecal neutrophil-derived biomarkers calprotectin and lactoferrin. Dig Dis 2013;31:336-344. 
15. Menees SB, Powell C, Kurlander J, Goel A, Chey WD. A meta-analysis of the utility of C-reactive protein, erythrocyte sedimentation rate, fecal calprotectin, and fecal lactoferrin to exclude inflammatory bowel disease in adults with IBS. Am J Gastroenterol 2015;110:444-454.

16. Koulaouzidis A, Douglas S, Rogers MA, Arnott ID, Plevris JN. Fecal calprotectin: a selection tool for small bowel capsule endoscopy in suspected IBD with prior negative bi-directional endoscopy. Scand J Gastroenterol 2011;46:561-566.

17. Kallel L, Ayadi I, Matri S, et al. Fecal calprotectin is a predictive marker of relapse in Crohn's disease involving the colon: a prospective study. Eur J Gastroenterol Hepatol 2010;22:340345.

18. Egea Valenzuela J, Pereñíguez López A, Pérez Fernández V, Alberca de Las Parras F, Carballo Álvarez F. Fecal calprotectin and C-reactive protein are associated with positive findings in capsule endoscopy in suspected small bowel Crohn's disease. Rev Esp Enferm Dig 2016;108:394-400.

19. Egea-Valenzuela J, Alberca-de-Las-Parras F, Carballo-Álvarez F. Fecal calprotectin as a biomarker of inflammatory lesions of the small bowel seen by videocapsule endoscopy. Rev Esp Enferm Dig 2015;107:211-214.

20. Jensen MD, Kjeldsen J, Nathan T. Fecal calprotectin is equally sensitive in Crohn's disease affecting the small bowel and colon. Scand J Gastroenterol 2011;46:694-700.

21. Kopylov U, Nemeth A, Koulaouzidis A, et al. Small bowel capsule endoscopy in the management of established Crohn's disease: clinical impact, safety, and correlation with inflammatory biomarkers. Inflamm Bowel Dis 2015;21:93-100.

22. Kopylov U, Yablecovitch D, Lahat A, et al. Detection of small bowel mucosal healing and deep remission in patients with known small bowel Crohn's disease using biomarkers, capsule endoscopy, and imaging. Am J Gastroenterol 2015;110:13161323.

23. Monteiro S, Barbosa M, Cúrdia Gonçalves T, et al. Fecal calprotectin as a selection tool for small bowel capsule endoscopy in suspected Crohn's disease. Inflamm Bowel Dis 2018;24:2033-2038.

24. Olsen PA, Fossmark R, Qvigstad G. Fecal calprotectin in patients with suspected small bowel disease: a selection tool for small bowel capsule endoscopy? Scand J Gastroenterol 2015;50:272-277.

25. Sipponen T, Haapamäki J, Savilahti E, et al. Fecal calprotectin and S100A12 have low utility in prediction of small bowel Crohn's disease detected by wireless capsule endoscopy. Scand J Gastroenterol 2012;47:778-784.

26. Aggarwal V, Day AS, Connor S, et al. Role of capsule endoscopy and fecal biomarkers in small-bowel Crohn's disease to assess remission and predict relapse. Gastrointest Endosc 2017;86:1070-1078.

27. Bar-Gil Shitrit A, Koslowsky B, Livovsky DM, et al. A pro- spective study of fecal calprotectin and lactoferrin as predictors of small bowel Crohn's disease in patients undergoing capsule endoscopy. Scand J Gastroenterol 2017;52:328-333.

28. Hale MF, Drew K, McAlindon ME, Sidhu R. The diagnostic accuracy of faecal calprotectin and small bowel capsule endoscopy and their correlation in suspected isolated small bowel Crohn's disease. Eur J Gastroenterol Hepatol 2016;28:1145-1150.

29. Kopylov U, Starr M, Watts C, Dionne S, Girardin M, Seidman EG. Detection of Crohn disease in patients with spondyloarthropathy: the SpACE Capsule Study. J Rheumatol 2018;45:498-505.

30. Yousuf H, Aleem U, Egan R, Maheshwari P, Mohamad J, McNamara D. Elevated faecal calprotectin levels are a reliable non-invasive screening tool for small bowel Crohn's disease in patients undergoing capsule endoscopy. Dig Dis 2018;36:202208.

31. Moher D, Liberati A, Tetzlaff J, Altman DG; PRISMA Group. Preferred reporting items for systematic reviews and meta-analyses: the PRISMA statement. Ann Intern Med 2009;151:264-269.

32. Cotter J, Dias de Castro F, Magalhães J, Moreira MJ, Rosa B. Validation of the Lewis score for the evaluation of smallbowel Crohn's disease activity. Endoscopy 2015;47:330-335.

33. Fireman Z, Mahajna E, Broide E, et al. Diagnosing small bowel Crohn's disease with wireless capsule endoscopy. Gut 2003;52:390-392.

34. Reitsma JB, Glas AS, Rutjes AW, Scholten RJ, Bossuyt PM, Zwinderman $\mathrm{AH}$. Bivariate analysis of sensitivity and specificity produces informative summary measures in diagnostic reviews. J Clin Epidemiol 2005;58:982-990.

35. Balduzzi S, Rücker G, Schwarzer G. How to perform a metaanalysis with R: a practical tutorial. Evid Based Ment Health 2019;22:153-160.

36. Doebler P, Holling H. Meta-analysis of diagnostic accuracy with mada [Internet]. Cran.r-project.org; c2015 [cited 2020 Nov 23]. Available from: https://cran.r-project.org/web/packages/mada/vignettes/mada.pdf.

37. Kopylov U, Klang E, Yablecovitch D, et al. Magnetic resonance enterography versus capsule endoscopy activity indices for quantification of small bowel inflammation in Crohn's disease. Therap Adv Gastroenterol 2016;9:655-663.

38. Choi M, Lim S, Choi MG, Shim KN, Lee SH. Effectiveness of capsule endoscopy compared with other diagnostic modalities in patients with small bowel Crohn's disease: a metaanalysis. Gut Liver 2017;11:62-72.

39. Hilmi I, Kobayashi T. Capsule endoscopy in inflammatory bowel disease: when and how. Intest Res 2020;18:265-274.

40. Annese V, Daperno M, Rutter MD, et al. European evidence based consensus for endoscopy in inflammatory bowel disease. J Crohns Colitis 2013;7:982-1018. 
41. Lobatón T, López-García A, Rodríguez-Moranta F, Ruiz A, Rodríguez L, Guardiola J. A new rapid test for fecal calprotectin predicts endoscopic remission and postoperative recurrence in Crohn's disease. J Crohns Colitis 2013;7:e641-e651.

42. Mosli MH, Zou G, Garg SK, et al. C-reactive protein, fecal calprotectin, and stool lactoferrin for detection of endoscopic activity in symptomatic inflammatory bowel disease patients: a systematic review and meta-analysis. Am J Gastroenterol 2015;110:802-819.

43. Sood R, Gracie DJ, Law GR, Ford AC. Systematic review with meta-analysis: the accuracy of diagnosing irritable bowel syndrome with symptoms, biomarkers and/or psychological markers. Aliment Pharmacol Ther 2015;42:491-503.

44. Turner D, Leach ST, Mack D, et al. Faecal calprotectin, lactoferrin, M2-pyruvate kinase and S100A12 in severe ulcerative colitis: a prospective multicentre comparison of predicting outcomes and monitoring response. Gut 2010;59:1207-1212.

45. Simon EG, Wardle R, Thi AA, Eldridge J, Samuel S, Moran GW. Does fecal calprotectin equally and accurately measure disease activity in small bowel and large bowel Crohn's disease? A systematic review. Intest Res 2019;17:160-170.

46. Tham YS, Yung DE, Fay S, et al. Fecal calprotectin for detection of postoperative endoscopic recurrence in Crohn's disease: systematic review and meta-analysis. Therap Adv Gastroenterol 2018;11:1756284818785571.

47. Stawczyk-Eder K, Eder P, Lykowska-Szuber L, et al. Is faecal calprotectin equally useful in all Crohn's disease locations? A prospective, comparative study. Arch Med Sci 2015;11:353361.

48. Zittan E, Kelly OB, Gralnek IM, Silverberg MS, Hillary Steinhart A. Fecal calprotectin correlates with active colonic inflammatory bowel disease but not with small intestinal Crohn's disease activity. JGH Open 2018;2:201-206.

49. Kopylov U, Yung DE, Engel T, et al. Fecal calprotectin for the prediction of small-bowel Crohn's disease by capsule endoscopy: a systematic review and meta-analysis. Eur J Gastroenterol Hepatol 2016;28:1137-1144. 